And what we have been introduced to by some of the data shown by Dr. Hull is that LMWH is going to take over. It's probably going to be the best method of treatment, one injection a day, send the patient home early. There is less bleeding, less recurrence, decreased mortality.

So we have entered into a new era, and there is no comparison of any form between thrombectomy, thrombolysis, and this modern, effective method of LMWH therapy.

And I come to the final question: If we are going to set up studies now so that in ten years' time there is some good evidence so we can make good recommendations, what sort of studies should we be setting up to compare thrombolysis versus adequate heparin therapy, thrombectomy versus adequate heparin therapy, or a combination? What's wrong with doing a thrombectomy and carrying on with proper heparin therapy?

I'd like to start with you, Russell, and then go to other members of the panel.

DR. HULL: In essence, you need different types of databases. You need clinical outcome trials that state whether the patient benefited or not, and that's straightforward.

You then need explanatory data to try and provide an explanation for the pathophysiology as it links to clinical outcome, and the analogy would be the pharmacology data with heparin and clinical outcome because both are crucial.

Then the issue is what type of pathophysiological end points do you wish to use? And my colleagues will answer those. There are a number.
DR. RUTHERFORD: Well, in terms of this particular issue, I think you'd have to have selected patients. I mean, you'd have to have inclusions and exclusions, obviously, and end up with a group of patients who might benefit.

You wouldn't apply this across the board to all DVT, obviously. You might end up with either three arms of therapy, or you might combine thrombolysis and thrombectomy in an interventional arm, using one or the other, depending on an algorithm like the one I showed, versus optional heparin usage.

And then finally, the outcome analysis will be crucial, and we've got to include a cost comparison in all of this, and include the complications to be able to do a real risk-benefit analysis at the end.

DR. NICOLAIDES: And what end points are you going to use?

DR. RUTHERFORD: My feeling is that we may have to use a combined end point of change in clinical class and some hemodynamic evidence of improvement.

Then you'd have a number of secondary end points. Quality of life will be important, and there's one now being developed and tested that combines standard quality-of-life measures with specific venous questions, which Tony Comerota is working on.

DR. NICOLAIDES: This is a key question. And I'd like all of you to think about it, and we'll come back to it tomorrow and on Sunday. What end points are we going to be using in future studies.

Well, thank you.

\title{
The Case for Aggressive Treatment of Pulmonary Embolism
}

\author{
Lazar J. Greenfield, MD \\ University of Michigan Hospitals. Ann Arbor, Michigan, USA
}

Effective management of pulmonary thromboembolism requires first and foremost that the diagnosis be confirmed. Under most circum- stances of "classical" signs and symptoms, when pulmonary angiography is obtained it will prove to be negative ( $71 \%$ in our experience). This com- 
pletely redirects the patient's management, often with recognition of unsuspected sepsis. When the angiogram is positive, simultaneous measurement of the pulmonary arterial pressure while the catheter is in the pulmonary artery allows classification of the patients based on the hemodynamic effects of the event in the patient (Table I).

Minor degrees of pulmonary thromboembolism are characterized by symptoms of cough, dyspnea, and anxiety with signs of tachypnea and tachycardia. Since these patients have not sustained a systemic hemodynamic effect, they are candidates for screening lung scan since a negative scan essentially excludes the diagnosis. A positive scan is subject to the criteria developed in the PIOPED study with reliance only upon a high probability reading. In the face of an intermediate probability reading, the diagnosis can be reinforced by duplex noninvasive venous examination, justifying a course of anticoagulation. Major pulmonary embolism can be defined as that degree of acute pulmonary vascular obstruction sufficient to produce systemic hypotension, which is usually transient and responds to resuscitation (Table I). When the hypotension is sustained and requires vasopressor support to maintain systemic blood pressure, the patient is considered to have massive pulmonary embolism and becomes a candidate for pulmonary embolectomy. If the patient has chronic recurrent thromboembolism, the presentation may be similar, but there are signs of chronic pulmonary hypertension and cor pulmonale.
Patients who are in shock are managed by administration of heparin (100-150 $\mu / \mathrm{kg})$ and placement of radial and pulmonary arterial catheters. After angiographic confirmation of the diagnosis with the patient remaining on the fluoroscopy table, a steerable cup-catheter* is inserted under local anesthesia through either the right femoral or internal jugular vein. The technique of catheter embolectomy has been described and modified recently only by more frequent use of the jugular rather than the femoral vein. The procedure is completed by insertion of a vena caval filter.

Transvenous catheter embolectomy is a safe, effective, and expeditious modality in patients with acute embolism who do not require continuous closed-chest cardiac massage. Forty-seven patients have been treated with this technique. Emboli were extracted successfully in 37 of them (79\%) with survival in $33(70 \%)$. In four of the last five cases, the indications were broadened to include patients who had become respirator dependent, and all had relief of pulmonary hypertension with rapid ability to wean from the respirator.

If catheter embolectomy fails, or if closedchest massage is required, open embolectomy should be performed on cardiopulmonary bypass. In our most recent experience, five of eight patients who underwent open embolectomy survived (63\%). Since catheter pulmonary embolectomy can be performed under local anesthesia in the radiology suite as soon as the diagnosis is confirmed, it represents an appropriate initial effort to treat major or massive pulmonary thromboembolism.

\section{Table I}

Stratification of Pulmonary Thromboembolism

\begin{tabular}{lllcl}
\hline Category & $\begin{array}{l}\text { Signs and } \\
\text { Symptoms }\end{array}$ & \multicolumn{1}{c}{ Gases } & $\begin{array}{c}\mathrm{PA} \\
\text { Occlusion (\%) }\end{array}$ & \multicolumn{1}{c}{ Hemodynamics } \\
\hline Minor & $\begin{array}{l}\text { Anxiety } \\
\text { Hyperventilation }\end{array}$ & $\begin{array}{l}\mathrm{PaO}_{2}<80 \mathrm{mmHg} \\
\mathrm{PaCO}_{2}<35 \mathrm{mmHg}\end{array}$ & $20-30$ & Tachycardia \\
Major & $\begin{array}{l}\text { Dyspnea } \\
\text { Collapse }\end{array}$ & $\begin{array}{l}\mathrm{PaO}_{2}<65 \mathrm{mmHg} \\
\mathrm{PaCO}_{2}<30 \mathrm{mmHg}\end{array}$ & $30-50$ & $\begin{array}{l}\text { CVP elevated, PA }>20 \mathrm{mmHg} \\
\text { Responds to resuscitation }\end{array}$ \\
Massive & $\begin{array}{l}\text { Dyspnea } \\
\mathrm{PaO}_{2}<50 \mathrm{mmHg}\end{array}$ & $>50$ & $\begin{array}{l}\text { CVP elevated, PA }>25 \mathrm{mmHg} \\
\text { Requires pressors, inotropes }\end{array}$ \\
& $\begin{array}{l}\mathrm{PaCO}_{2}<30 \mathrm{mmHg} \\
\text { Chock }\end{array}$ & $\begin{array}{l}\text { CVP elevated, PA }>40 \mathrm{mmHg} \\
\mathrm{PaO}_{2}<70 \mathrm{mmHg}\end{array}$ & $>50$ & $\begin{array}{l}\text { Fixed low cardiac output } \\
\mathrm{PaCO}_{2} 30-40 \mathrm{mmHg}\end{array}$ \\
& $\begin{array}{l}\text { Dyspnea } \\
\text { Syncope }\end{array}$ & &
\end{tabular}




\section{Reading List}

1. Langham MR Jr, Greenfield LJ: Transvenous catheter embolectomy for life-threatening pulmonary thromboembolism. Inf in Surg 5:694, 1986.

2. Greenfield LJ: Invited editorial comment. In: Moore JH Jr, Koolpe HA, Carabasi RA, Yang SL, Jarrell BE: Transvenous catheter pulmonary embolectomy. Arch Surg 120:1375, 1985.
3. Stewart JR, Greenfield LJ: Transvenous vena caval filtration and pulmonary embolectomy. Surg Clin North Am 62:411-430, 1982.

4. PIOPED Investigators: Value of the ventilation/perfusion scan in acute pulmonary embolism. JAMA 263:2753, 1990.

* MediTech, Inc., Watertown, Pa

\title{
The Case Against Aggressive Treatment in PE
}

\author{
Thomas M. Hyers, MD \\ Saint Louis University School of Medicine, St. Louis, Missouri, USA
}

The natural history of pulmonary embolism indicates that in most cases conservative treatment with properly administered anticoagulants is sufficient. These studies have shown that pulmonary emboli occur in clusters in most patients before the process is diagnosed. When proper therapy with heparin and warfarin are initiated, the short-term outcome is usually good. Although natural history studies show that some $25 \%$ of patients with pulmonary embolism die in the year following diagnosis, most of these individuals die of comorbidity and not directly from venous thromboembolism. Only $10 \%$ of deaths in the year following pulmonary embolism occur from recurrent pulmonary embolism. The other $90 \%$ of deaths are attributable to preexisting disease which is usually cardiopulmonary disease or cancer.

This thesis is predicated on the proper use of heparin and warfarin. Heparin must be given in sufficient quantity, monitored, and dose-adjusted to halt the progression of thrombus so as to allow the body's natural processes to resolve the thrombus. This goal has always been problematic because of the unpredictable kinetics of heparin. Warfarin also must be given in the proper amount to achieve an INR in the range of 2-3 long term to allow the resolution of the thrombophilic process. In some cases patients with ongoing predispositions to pulmonary embolism such as malignancy or inherited thrombophilic conditions will require anticoagulation with warfarin beyond the usually prescribed three to six months.

The advent of low-molecular-weight heparins opens a new era in the treatment of venous thrombosis. Low-molecular-weight heparins can be given on a weight-based dosing regimen without subsequent monitoring or dose adjustment. In comparison to standard heparin, LMWH is more likely to arrest thrombus growth and reduces the rates of bleeding and thrombocytopenia. This allows for more effective therapy with a stronger likelihood of completely arresting the thrombotic process. In addition, LMWHs offer the opportunity for outpatient treatment or early hospital discharge in selected stable patients. LMWHs should enhance our ability to treat most patients with pulmonary embolism without the use of more invasive therapy.

The few patients who die immediately of pulmonary embolism usually do so before any medical or surgical therapy can be instituted. Patients who survive for at least one hour with pulmonary embolism are very likely to survive for the long term if proper anticoagulation is promptly instituted. In this setting, a few selected patients can benefit from the use of thrombolytic therapy. Although there is no controlled clinical evidence that thrombolytic therapy reduces mortality in acute massive pulmonary embolism, clinical experience has shown it to be effective in the selected patient with life-threatening pulmonary embolism who is hemodynamically unstable. Given this approach to therapy, surgical intervention for acute pulmonary embolism should be reserved for the very few patients who are hemodynamically unstable and not candidates for thrombolytic therapy. 